\title{
The Effectiveness of Using Multisensory Approach in Enhancing Achievement and Retention of English Vocabulary Amongst Intermediate Female Students with EFL Learning Disabilities
}

\author{
Nada Saad Algrni \\ English language Teacher, Ministry of Education PO box 26523, Taif 7044, Saudi Arabia
}

\begin{abstract}
The aim of this study was to investigate the effectiveness of using multisensory approach in enhancing the achievement and retention of English language vocabulary amongst intermediate stage female students with EFL learning disabilities. A quasi-experimental model was adopted as an experimental methodology where a standardized intelligence test (R.Cattel IQ scale) and a researcher -prepared vocabulary achievement test were used as research tools. The subjects $(\mathrm{N}=116)$ were selected from two intermediate schools in Taif. A criterion was applied to select students with learning disabilities. The sample was divided randomly into two groups: control and experimental. Both groups were pre-tested to assure that they were equivalent. The control group $(\mathrm{N}=10)$ were taught through traditional method, while the experimental group $(\mathrm{N}=12)$ were taught through multisensory approach during the first term of the school year(1435-1436H). The experiment lasted for six weeks, then the vocabulary achievement was applied. One month later, the VAT delayed test was applied. In order to process the results of the study groups statistically, the researcher used the computerized program: Statistical Package for Social Sciences (SPSS). Mann-Whitney U Test, normal distribution Z, Wilcoxon signed ranks test and effect size of Wilcoxon were used in this study. Results revealed that multisensory approach had a positive effect on vocabulary achievement and retention of the students with learning disability.
\end{abstract}

Keywords: Multisensory Approach, EFL, Learning Disabilities, English Vocabulary, KSA.

DOI: $10.7176 / \mathrm{JEP} / 11-9-17$

Publication date:March $31^{\text {st }} 2020$

\section{Introduction}

Over the recent decades, learning English language has gained increased importance because English is the most widely used language for the expression of knowledge in all professional fields. In fact, the benefits of learning English as a second or a foreign language are not restricted to advancing in the professional life but people may also get experiences which have more to do with their mental, emotional and cultural growth.

To achieve a successful process of learning English, one must acquire its vocabulary, grammar, pronunciation and the four skills: listening, reading, speaking, and writing. Vocabulary is a vital part of language that students need to master in order to communicate effectively. Moreover, it is considered the base for the other skills. According to Keshta and Al-Faleet (2013, pp.46-47), the ability to grasp the meaning of new words is a necessary skill to strengthen reading and listening comprehension. This can positively impact overall academic success and can develop skills for real world applications. Hence, Language learners need effective ways to increase opportunities for acquiring and retaining new words in long-term memory.

Forgetting the new words is a common problem in learning a second or a foreign language. learners often complain that they forget new words soon after learning them (Komachali and Khodareza,2012, p.135). Lin (2003, p.65) pointed that there are several problems facing learning English vocabulary. These include forgetting new vocabulary because learners do not use them in their daily life since they are not surrounded by English speakers. This problem of forgetting tends to largely affect students with learning disabilities. Adults and children with learning disabilities often have difficulty recalling information that they have seen, or heard, or both. Additionally, learners have trouble memorizing and remembering the spelling of new vocabulary coupled with difficulty in pronunciation due to the insufficiency of the existing teaching methods. The lack of teachers` understanding of the LD students' needs can be considered a major reason for choosing insufficient teaching methods.

Many people may face difficulty in understanding what learning disability means. Actually, it is an umbrella term that describes a wide variety of disorders. A student can have a learning disability that is either general or specific in nature. A specific learning disability is very different to a general learning disability. Students with general learning disabilities (GLD) find it more difficult to learn, understand and do things than other students of the same age. Students with specific learning disabilities have difficulty in a specific area of learning such as reading, writing, spelling and arithmetical notation. According to The National Council for Special Education NCSE (2014, p.30), their difficulties are very specific and are not due to other causes such as their general ability being below average, defective sight or hearing, emotional factors or a physical condition. Individuals with Disabilities Education Act (IDEA), the federal law that provides for special education, defines specific learning disability as: "a disorder in one or more of the basic psychological processes involved in understanding or in using 
language, spoken or written, that may manifest itself in the imperfect ability to listen, think, speak, read, write, spell, or do mathematical calculations, including conditions such as perceptual disabilities, brain injury, minimal brain dysfunction, dyslexia, and developmental aphasia. Specific learning disability does not include learning problems that are primarily the result of visual, hearing, or motor disabilities, of mental retardation, of emotional disturbance, or of environmental, cultural, or economic disadvantage.” (Turnbull, 2005, p.11).

Researchers think that learning disabilities are caused by differences in how a person's brain works and how it processes information. Students with learning disabilities are not "dumb" or "lazy." In fact, they usually have average or above average intelligence. Their brains just process information differently (Luke, 2011, p.1). Since almost five percent of all students in schools are classified as having specific learning disabilities (SLD), every teacher can expect to find students with learning disabilities in the classroom (Asghar et al., 2017). Success for these students in learning English language requires using effective teaching techniques to help them acquire and retain vocabulary.

One of the most effective techniques in teaching LD students is the use of the multisensory approach. The International Dyslexia Association (2000) defines the multisensory approach as learning through "simultaneously visual, auditory, and kinesthetic-tactile (pathways) to enhance memory and learning. Links are consistently made between the visual (what we see), auditory (what we hear), and kinesthetic-tactile (what we feel) pathways in learning to read and spell"(p.3). The idea that learning experienced through all the senses is helpful in reinforcing memory has a long history in pedagogy. From the earliest teaching guides of Montessori, educators have embraced a range of multisensory techniques in order to make learning richer and more motivating for learners (Joshi et al. 2002, P.2). Multisensory lessons incorporate several learning pathways in the brain at the same time so that opportunities for memory and learning are increased. Instead of telling students information, the goal is to engage the students so that they are doing the work and therefore doing the learning. Pickering (2004, p.3) indicated that LD students do not proceed smoothly through the sensitive periods as the normal student does. Chau (2011, P.4) added that they have areas of strength and areas of weakness as some perceptual areas are "arrested" at a younger level of development, so the more information is coming in through the senses, the more likely it is that the student will find a piece of that information relevant or interesting and give it a second look which will help the information be committed to memory.

Recent research proved the effectiveness of the multisensory approach in improving students' achievement in all ages and subjects for both normal and LD students. An example of examining the impact of the multisensory approach is a study by Guyre and Sabatino (2001), which studied college students who are diagnosed as having learning disabilities to determine if they would make more progress if taught by the Orton-Gillingham technique, which is derived from the multisensory approach. The O-G group was found to achieve statically significant improvement in reading when compared with the control group. This indicates that using a modified O-G technique is useful in the teaching of reading to college students who are LD. Also, Dev, Doyle, and Valente (2002) used the Orton-Gillingham technique that involves visual, auditory, and kinesthetic modalities, with first grade children at the special education level. These children improved enough in their reading abilities to advance them out of the special education level. Moreover, Joshi, Dahlgren, and Boulware-gooden (2002) examined the effects of using a multisensory approach to teaching reading with first graders. The researchers noted and concluded that using the multisensory approach was very effective. Alesio, Scalia and Zabel (2007) used a multisensory, direct instructional approach to improve student vocabulary acquisition in second and seventh grade classrooms. The post data from all three target schools show that the solution strategy implemented definitely improved the vocabulary acquisition of the target students. Among other researchers who defended the effectiveness of multisensory approach are Garcia (2010), Jubran (2011), Phillips and Feng (2012), Hettiarachchi and Ranaweera (2013).

Review of the previous studies revealed that, despite the various studies that investigated the effectiveness of the multisensory approach, using this approach to enhance vocabulary achievement and retention for students with learning disabilities is not given enough attention. To the best of the researcher's knowledge, the present study is the first study to investigate the effectiveness of using the multisensory approach in enhancing English vocabulary achievement and retention of intermediate grade students with EFL learning disabilities. The present study is of a great value for EFL teachers, who are not qualified to support students with foreign language learning disabilities, because it provides a teacher's guide that presents a proposed multisensory model which could be applied by EFL teachers to help students overcome language learning disability. This study may hopefully raise the awareness of all those who deal with LD students to provide proper support for them.

\section{Research objectives}

The major objective of the current study is to investigate the effectiveness of using multisensory approach in enhancing the achievement and retention of English language vocabulary amongst intermediate stage female students with EFL learning disabilities.

\section{Research Problem}


The researcher observed that students are facing difficulty with English vocabulary achievement and retention. Informal interviews with professional colleagues from different schools proved that language and their vocabulary achievement. This is supported by a variety of studies such as Lin (2002), Komachali and Khodareza (2012) and Al-Zahrani (2011) who found that language learners often complain that they forget new words soon after learning them. Jones (2005, para.3) also mentioned that most students - not just those with learning problems - rarely remember the meaning of new terms beyond the test.

Moreover, the researcher found that strategies and activities involved in the students ' book and in the teacher's guide seem to ignore students with learning disabilities as they provide the same instruction for all students regardless of their different needs and different learning styles. Also, the importance of vocabulary learning poses the need to know an instructional program that might foster the acquisition and retention of so many words for learners with different abilities. Based on literature, the problem of the present study can be formulated as follows:

Students from the 2 nd intermediate stage seem to face difficulty in English vocabulary achievement and retention, particularly, those with learning disabilities. This difficulty may be due to the insufficiency of the existing course activities and teaching methods.

In the light of the abovementioned, the research problem could be summarized in the following question:

What is the effectiveness of the multisensory approach in enhancing English vocabulary achievement and retention of 2 nd intermediate grade students with learning disabilities?

\section{Research Hypothesis}

In the light of the research problem and literature review, the researcher came up with the following hypothesis

1. There is no statistically significant difference at level $(\alpha \leq 0.05)$ between the mean rank scores obtained by the study groups (experimental and control) in the post application of the vocabulary achievement test (VAT).

2. There is no statistically significant difference at level $(\alpha \leq 0.05)$ between the mean rank scores obtained by the study groups (experimental and control) in the delayed application of the vocabulary achievement test (VAT).

3. There is no statistically significant difference at level $(\alpha \leq 0.05)$ between the mean rank scores obtained by the students of the control group in the pre and post applications of the vocabulary achievement test (VAT).

4. There is no statistically significant difference at level $(\alpha \leq 0.05)$ between the mean rank scores obtained by the students of the experimental group in the pre and post applications of the vocabulary achievement test (VAT).

5. There is no statistically significant difference at level $(\alpha \leq 0.05)$ between the mean rank scores obtained by the students of the control group in the post and delayed applications of the vocabulary achievement test (VAT).

6. There is no statistically significant difference at level $(\alpha \leq 0.05)$ between the mean rank scores obtained by the students of the experimental group in the post and delayed applications of the vocabulary achievement test (VAT).

\section{Literature Review}

\subsection{Learning Disability}

Learning disabilities are the most common type of disability in the field of special education. Currently, more students are identified as having specific learning disability than any other type of disability. A learning disability is thought to be a neurological disorder that affects the brain's ability to receive, process, store, and respond to information (National Research Center for Learning Disabilities, 2007, para.1). The term "learning disability" is used to explain difficulty a person of at least average intelligence has in acquiring basic academic and functional skills. Learning disabilities can affect a person's ability to understand or use spoken or written language, do mathematical calculations, coordinate movements, or direct attention.

Being a successful FL learner is vital both during the school years and also later in life. In addition to causing problems with the progress of studies, getting into schools and getting jobs, language disabilities may also affect a person's self-esteem (Viskari, 2005, p.8).Bad memories of the FL classes in school may haunt people through their life and prevent them from getting into situations where using a foreign language would be needed. On the other hand, it is important to note that knowing a foreign language can offer experiences such as enjoying FL literature and communicating with foreign people. So, the benefits of knowing a foreign language are not restricted to advancing in life but people may also get experiences which have more to do with their emotional growth. Being able to learn and use a foreign language is an ability that opens many doors and it should not be denied of people with learning disabilities. Foreign language teachers often face the challenging task of teaching students with disabilities. This is a challenge for foreign language teachers because they are not prepared to teach students with disabilities and often do not have a teacher's aide proficient enough to assist them. In order to face this challenge, 
it is important for the FL teachers to understand what learning disabilities mean, what causes learning disabilities and FL learning disabilities and how to Identify and teach FLLs with learning disabilities.

5.1.1 Definition of Learning Disability

When researching information, one finds a multitude of different definitions for the term "learning disabilities" that have evolved over time. Learning disability is an umbrella term that describes a wide variety of disorders. Generally speaking, people with learning disabilities are of average or above average intelligence. There often appears to be a gap between the individual's potential and actual achievement. This is why learning disabilities are referred to as "hidden disabilities": the person looks perfectly "normal" and seems to be a very bright and intelligent person, yet may be unable to demonstrate the skill level expected from someone of a similar age (LDA, 2015, para.4).

According to Dr. Samuel Kirk (1962), who was the first to originate and use the term learning disabilities, a learning disability refers to: "a retardation, disorder, or delayed development in one or more of the processes of speech, language, reading, spelling, writing, or arithmetic resulting from a possible cerebral dysfunction and/or emotional or behavioral disturbance and not from mental retardation, sensory deprivation, or cultural or instruction factors".( p.263)

The National Joint Commission on Learning Disabilities (NJCLD) ( 1998) defines learning disabilities as "a general term that refers to a heterogeneous group of disorders in the acquisition and use of listening, speaking, reading, writing, reasoning, or mathematical abilities, presumed to be due to central nervous system dysfunction, and may occur across the life span. Problems in self-regulatory behaviors, social perception, and social interaction may exist with learning disabilities, but do not by themselves constitute a learning disability. Although learning disabilities may occur concomitantly with other handicapping conditions (for example, sensory impairment, mental retardation, serious emotional disturbance) disability. or with extrinsic influences (such as cultural differences, insufficient or inappropriate instruction). (p.1)

In addition, learning disabilities are defined as " a general set of disorders that can affect a person's ability in the areas of listening, speaking, reading, writing, and mathematics" (Bridges to Practice, 1995, p.3).

Learning Disabilities Association of Ontario, Canada, LDAOC (2011, para.2) defines Learning disabilities as a variety of disorders that affect the acquisition, retention, understanding, organization, or use of information. This information is not only academic information - LDs can affect any information: social information, physical information, verbal information. These disorders result from impairments in one or more psychological processes related to learning, and affect specific areas of learning in one person - not all areas. People with LDs have average (or greater) abilities for thinking and reasoning. Learning disabilities range in severity and invariably interfere with the acquisition and use of one or more of the following important skills:

- Oral language (e.g., listening, speaking, understanding)

- $\quad$ Reading (e.g., decoding, comprehension)

- Written language (e.g., spelling, written expression)

- Mathematics (e.g., computation, problem solving)

- Organization (e.g., planning, follow-through)

- $\quad$ Social Skills (e.g., social perception and interaction)

Additionally, an operational definition of a learning disabled student introduced by Elbanna (2000, p.6) states that a disabled student shows a discrepancy between expected performance (as measured by IQ scale) and real performance (as measured by achievement test) and that is shown as underachieving in achievement test in comparison to students of the same age and intelligence . students with visual, auditory or motor deficits are excluded. According to Elbanna (2000, p.6), students with learning disabilities are diagnosed through exclusion criterion and discrepancy criterion. A student is classified as learning disabled when the discrepancy between the Z-scores of expected achievement and actual achievement is one standard deviation or more.

The present study defines students with learning disabilities as those who have average to above average intelligence, but show a severe discrepancy between actual achievement and intellectual abilities. Students with learning disabilities do not include learning problems that are the result of visual, hearing, or motor disabilities; of intellectual disability; of social or emotional disturbance; or of environmental, educational, cultural, or economic disadvantage. A student is classified as learning disabled when the discrepancy between the Z-scores of expected achievement and actual achievement is one standard deviation or more.

\subsection{The Multisensory Approach}

The Multisensory approach teaches the student how to learn by teaching traditional subject matter in a nontraditional manner. It does not cure learning disabilities but it goes around it to help students learn.

\subsubsection{Definition of The Multisensory Approach}

Multisensory approach, "also known as VAKT (visual-auditory kinesthetic-tactile) implies that students learn best when information is presented in different modalities (Mercer \& Mercer, 1993 as cited in Murphy, 1997, p. 1). The International Dyslexia Association (2000, p.3) defines Multisensory Approach as "simultaneously visual, 
auditory, and kinesthetic-tactile to enhance memory and learning. Links are consistently made between the visual (what we see), auditory (what we hear), and kinesthetic-tactile (what we feel) pathways in learning to read and spell. Sprenger (2008, p.30) defines it as continual use of the five senses, including the use of body movement, to teach abstract concepts, making them concrete and accessible for memory, usage, and transference. Using several modalities at one time to strengthen neural pathways. The Online Free Dictionary by Farlex (2009) defines multisensory as "relating to or involving several bodily senses".

The term (Multi-sensory learning) is used to refer to any learning activity that combines two or more sensory strategies to take in or express information. It is most properly understood and practiced as an approach, not a method, program, system or technique. (Academy of Orton-Billingham Practitioners and Educators, 2012, para.1). In general, it means presenting all information to students via the sensory modalities: visual, auditory, kinesthetic and tactile. It focuses on connecting the channels of perception to create conditions for learning and fixing the language. Visual presentation techniques include graphic organizers, drawing to express learning and displays of pictures, posters and students work for reinforcing instruction; auditory presentation techniques include conducting thorough discussions, chanting and reading aloud; tactile presentation techniques include manipulating blocks and objects students can hold in their hands; kinesthetic presentation includes sequence of movements, practical tasks, acting and playing. Activities that harness all the senses are an excellent way to include learners with learning disabilities. This can be summed up in the phrase "hear it, say it, see it and write it".

5.1.2Related Theories

The philosophy behind multimodal learning is not a new one. Maria Montessori and John Dewey developed techniques based on multisensory learning and multiple intelligences which include, among others, tactile letters. They viewed the classroom as a social microcosm in which children may develop themselves following their natural tendencies (Garcia,2010, p.5).

In 1948, the American psychologist Benjamin Bloom discovered three different domains to be significant in the learning process, the Cognitive domain (based on mental skills); the Affective domain (based on feelings and emotions); and the Psychomotor domain (based on physical skills) (Garcia, 2010, p.7).

In this regard, we may also consider Communicative Language Learning (CLL). CLL is cooperative learning that stresses the role of the affective domain in promoting cognitive learning (Garcia, 2010, p.6). Developed by Charles Curran in 1976, the basic theoretical premise is that the human individual needs to be understood and aided in the process of fulfilling personal values and goals. This learning process is best done in community. In CLL classroom dynamics, the lesson was comprised of six to twelve learners seated in a close circle. One or two teachers stood outside ready to help. Techniques were used to reduce anxiety and promote students' expression of ideas and feelings (Garcia, 2010, p.6).

The idea of individualized learning styles originated in the 1970s and has greatly influenced education. In learning styles theory, the educator looks at the individual student and identifies the student's preferred styles or intelligence to learn. The educator uses a learning styles inventory to assess which learning styles and intelligence lead the student to succeed and which don't. The teacher then tries to design learning activities that integrate the student's learning styles (Moustafa,1999, p.5).

Also, the theory of multiple intelligences, which was proposed by Howard Gardner in his 1983 book (Frames of Mind: The Theory of Multiple Intelligences), differentiates the intelligences into specific (primarily sensory) "modalities", rather than seeing intelligence as dominated by a single general ability. Gardner has identified eight bits of intelligence: 1) linguistic, 2) logical-mathematical, 3) musical-rhythmic, 4) visual-spatial, 5) bodilykinesthetic, 6) interpersonal, 7) intrapersonal, and 8) naturalist (Voltz et al.,2010, p.3)

The Total Physical Response (TPR) was developed as a modern adaptation of the Direct Method by James Usher. This method is known for its use of oral commands which students have to carry out to show their understanding. Nowadays, it is mainly used to teach children a foreign language in their first years at school. It has verified its power to teach some vocabulary regarding verbs of movement which involves easy demonstration by students (Garcia, 2010, p.6).

\subsection{Vocabulary Achievement and Retention}

Vocabulary is one of five core components of reading instruction that are essential to successfully teach students how to read. These core components include phonemic awareness, phonics and word study, fluency 'vocabulary, and comprehension (National Reading Panel, 2000, p.15). Vocabulary also is a principle contributor to comprehension, fluency, and achievement. Vocabulary development is both an outcome of comprehension and a precursor to it, with word meanings making up as much as 70-80\% of comprehension (Bromley, 2007, p.528). A report of The National Reading Panel (2000, p.3) states that a large vocabulary is more especially predictive and reflective of high levels of reading achievement. The panel also notice that the importance of vocabulary knowledge has been recognized in the development of reading skills. The report also states that as early as 1924 it has been shown that growth in reading relied on continuous growth in word knowledge.

Lack of adequate vocabulary knowledge is already an obvious and serious obstacle for many students in 
reading and using English language. Teaching vocabulary well is a key aspect of developing engaged and successful language learners. Corbett $(2009$, p.27) states that vocabulary instruction and word knowledge could contribute to improved comprehension and that it could provide a sound rationale for increased emphasis on vocabulary instruction.

\section{Method and Procedures}

\subsection{Research Design and Sample}

The present study adopted the quasi-experimental model of the experimental methodology. Two research groups were involved: the experimental group and control group. The experimental group was taught vocabulary of English language book of 2nd intermediate grade (Lift Off), first term from unit 4 to 7 through the multisensory approach. The control group was taught the same vocabulary through traditional method. The experimental group received treatment for six weeks while the control group was exposed to the traditional teaching for the same period. This design included the following variables: an independent variable: the multisensory approach and two dependent variables: vocabulary achievement and vocabulary retention.

The population of the study was 2 nd intermediate grade female students who were registered in the Ministry of Education for the academic year 2015. The researcher selected this grade because of the availability of the student's English language marks of the previous year (i.e first intermediate grade), which is a vital criterion in determining students with learning disabilities. Another reason for choosing this grade is that applying the multisensory approach is better in earlier years of studying and the second intermediate grade is considered an early year of studying English as a foreign language in Saudi Arabia.

The subjects $(\mathrm{N}=116)$ were selected from two intermediate schools in Taif city: 34th intermediate school and 45th intermediate school. Two classes were selected from three classes in the 34th intermediate school to represent the experimental group $(\mathrm{N}=52)$. These two classes were the first and the second.

Also, two classes were selected from three classes in the 45th intermediate school to represent the control group $(\mathrm{N}=64)$. These two classes were the first and the third. Each class consists of normal students and students with EFL learning disabilities because it was difficult to isolate students with EFL learning disabilities in separate classes.

\subsection{Research Method and Procedure}

An Arabic version of Cattle intelligence test cultural free scale 2 translated into Arabic by Salamah and Abdulghaffar (1974) was adopted as a pretest to pinpoint students with EFL learning disabilities. This test depends on graphics to estimate students' intelligence from the age of 8 to 13 and it could be used for adults. The correlation coefficient between the students' scores in Cattle IQ test and their scores in the vocabulary achievement test was 0.53 which is significant at level 0.01. Using Alpha Cronbach, a high reliability level of 0.78 was obtained for the R. Cattle IQ test.

In addition, the VAT was prepared by the researcher to be used as a pretest, posttest and delayed test. It was used as a pretest to determine the homogeneity of the students in both groups (control and experimental) before being exposed to the traditional method and the multisensory method of teaching vocabulary. Also, it was used as a post test for both groups to measure their vocabulary achievement. Again, the same test was used as a delayed test after one months from administering posttest in order to measure vocabulary retention of both groups too. The first version of the test, which consisted of 40 items, was validated by specialist reviewers whose comments were considered when refining the final version.

The researcher taught the units 4,5,6 and 7 to the experimental group. The assigned vocabulary was taught by using the multisensory method. Vocabulary lessons were not separated from other lessons. The same order of the lessons in the student's book (Lift Off) was followed. The control group was taught the same vocabulary by their teacher using the traditional method. The researcher preferred not to teach the control group in order to avoid the effect of unintentional use of the researcher's skill in teaching via the multisensory method while teaching the control group. For that reason, the researcher chose a control group whose teacher had an experience in teaching English language that is almost as the researchers ' experience. The teaching lasted for six weeks: four sessions per week. Each session lasted for 45 minutes.

The lesson started with oral warm up. Then, the new vocabulary was introduced through flash cards, real objects, video clips or acting. For each word; the new vocabulary written in the flash card was read aloud then each letter sound was spelled and the word was repeated again as students repeat after the researcher. Students were asked to sky write the new word three times while looking to the flash card that is, to write it in large, imaginary letters in the air, using the large muscles of their arms as they simultaneously say the word or letter aloud, once the large muscles are involved in learning, the muscle memory will aid students when they cannot "picture" the word in their minds.

Movement and sounds were used to enhance words recalling. Students should repeat and drill the word in coral then read it individually. They were asked to spell the word as they write it on their mini dry- erase boards. 
The researcher provided example sentences that showed how to use the word. After that, work sheets were given to the students to practice what they learned. Finally, the researcher assigned a homework that encouraged students to use the words more effectively.

After teaching the assigned units, the vocabulary achievement posttest was administrated to the study groups in order to measure their vocabulary achievement.

One month later, the delayed vocabulary achievement test was administrated to the study groups in order to measure their vocabulary retention.

In order to process the results of the study groups statistically, the researcher used the computerized program: Statistical Package for Social Sciences (SPSS). Mann-Whitney U Test, normal distribution Z, Wilcoxon signed ranks Test and effect size of Wilcoxon were used in this study.

\section{Results and Discussion}

7.1 Testing the First Hypothesis

The first hypothesis states that "There is no statistically significant difference at level $(\alpha \leq 0.05)$ between the mean rank scores obtained by the study groups (experimental and control) in the post application of the vocabulary achievement test (VAT)".

To test the first hypothesis, the mean, the standard deviation and the standard error mean were computed. Mann-Whitney U Test, the non - parametric alternative of T test, was used to compare the mean ranks of two independent groups. $\mathrm{Z}$ value (the alternative normal distribution of $U$ ) was also calculated. The following two tables show the results:

Table (1): The Mean, Standard deviation and standard error mean for scores of LD students of the experimental and control groups in the post - test.

\begin{tabular}{|c|c|c|c|c|c|c|}
\hline Group & $\mathrm{N}$ & Mean & \multicolumn{2}{|c|}{ Std. Deviatio $n$} & \multicolumn{2}{|c|}{ Std. Error Mean } \\
\hline Control & 10 & 8.4000 & \multicolumn{2}{|l|}{5.73876} & \multicolumn{2}{|c|}{1.449} \\
\hline Experiment al & 12 & 28.9167 & 7.79812 & 1.960 & & \\
\hline \multicolumn{7}{|c|}{ Table (2): Mann-Whitney U value for comparing mean ranks of two independent groups in the post -test. } \\
\hline Group & $\mathrm{N}$ & Mean Rank & Sum of Ranks & Mann-Whitney U & Z & $\mathrm{P}$ \\
\hline Control & 10 & 5.70 & 57.00 & \multirow{2}{*}{2.0} & \multirow{2}{*}{3.828} & \multirow{2}{*}{0.01} \\
\hline Experimental & 12 & 16.33 & 196.00 & & & \\
\hline
\end{tabular}

The results demonstrated in table (2) show that, the value of Zobs $=3.828$ is more than the critical value for a two tailed statistical test $\mathrm{Zcv}=1.96$ at significance level $(\alpha \leq 0.05)$. This implies that, there is a statistically significant difference between the mean ranks of students` scores in the experimental and control groups. The total ranks for the experimental group $\sum \mathrm{R} 1=196.00$ is more than the total ranks for the control group $\sum \mathrm{R} 2=57.00$, which makes the difference goes for the favor of the experimental group. This means that, the difference is due to the experimental treatment not to coincidence. In the light of this result, the null hypothesis (H0) is rejected and the alternative hypothesis (H1) is accepted.

The alternative hypothesis states that "There is a statistically significant difference at $(\alpha \leq 0.05)$ level between the mean rank scores obtained by the study groups (experimental and control) in the post course application of the vocabulary achievement test (VAT) to the favor of the experimental group".

It is observed that this result agrees with the findings of some previous studies as Tolbert (2013) and Ashouri and Moghadam (2015) that assured the superiority of the multisensory method over the traditional method in enhancing vocabulary achievement. On the other hand, Caprio (2011) indicated that while multisensory method did increase students' vocabulary achievement, so did the traditional method. The reason for this result of Caprio (2011) could be the severity of the disabilities the students had.

In both cases, the studies that agrees with this result or the one that find it as effective as the traditional method, the multisensory method is proved to be effective in teaching students with learning disabilities.

\subsection{Testing the Second Hypothesis}

The second hypothesis states that " There is no statistically significant difference at level $(\alpha \leq 0.05)$ between the mean rank scores obtained by the study groups (experimental and control) in the delayed application of the vocabulary achievement test (VAT)".

To test this hypothesis, the mean, the standard deviation and the standard error mean were computed. MannWhitney U Test, the non - parametric alternative of T test, was used to compare the mean ranks of two independent groups. $Z$ value, the alternative normal distribution of Mann-Whitney U value, was also calculated. The following two tables show the results: 
Table (3): The Mean, Standard deviation and standard error mean for scores of LD students of the experimental and control groups in the delayed application of VAT.

\begin{tabular}{|l|l|l|l|l|}
\hline group & $\mathrm{N}$ & Mean & Std. Deviation & Std. Error Mean \\
\hline Control & 10 & 7.4000 & 3.94968 & 1.24900 \\
\hline Experimental & 12 & 23.5000 & 10.25582 & 2.96060 \\
\hline
\end{tabular}

Table (4): Mann-Whitney U value for comparing mean ranks of two independent groups in the delayed application of VAT.

\begin{tabular}{|l|l|l|l|l|l|l|}
\hline group & $\mathrm{N}$ & Mean Rank & Sum of Ranks & MannWhitney U & $\mathrm{Z}$ & $\mathrm{P}$ \\
\hline Control & 10 & 6.15 & 61.50 & \multirow{2}{*}{6.500} & \multirow{2}{*}{3.536} & \multirow{2}{*}{0.01} \\
\cline { 1 - 4 } Experimental & 12 & 15.96 & 191.50 & & & \\
\hline
\end{tabular}

The results in table (4) show that, the value of Zobs $=3.536$ is more than the critical value for two tailed statistical test $\mathrm{Zcv}=1.96$ at significance level $(\alpha \leq 0.05)$. This implies that, there is a statistically significant difference between the mean rank scores of students in the experimental and control groups. The total ranks for the experimental group $\sum \mathrm{R} 1=191.50$ are more than the total ranks for the control group $\sum \mathrm{R} 2=61.50$, which makes the difference goes for the favor of the experimental group. This means that, the difference is due to the experimental treatment not to coincidence. In the light of this result, the null hypothesis (H0) is rejected and the alternative hypothesis (H1) is accepted.

The alternative hypothesis states that "There is a statistically significant difference at $(\alpha \leq 0.05)$ level between the mean rank scores obtained by the study groups (experimental and control) in the delayed application of the vocabulary achievement test (VAT) to the favor of the experimental group".

This result is in line with the study of Nemati (2009), Tolbert (2013) and Ashouri and Moghadam (2015) that ensured the effectiveness of the multisensory method in enhancing retention. This attribute of the multisensory method is due to the use of as much senses as possible that subsequently leads to better attention to details and better retention of what is being learned.

\subsection{Testing the third hypothesis}

The third hypothesis states that "There is no statistically significant difference at level $(\alpha \leq 0.05)$ between the mean rank scores obtained by the students of the control group in the pre and post applications of the vocabulary achievement test (VAT)".

To test this hypothesis, Wilcoxon Signed Ranks Test, the non - parametric alternative of T test for two related samples, was used. $Z$ value, the alternative normal distribution of Wilcoxon value, was also calculated as shown in the following table (5):

Table (5): Wilcoxon Signed Ranks value for comparing mean ranks of the control group in the pre and post application of VAT.

\begin{tabular}{|l|l|l|l|l|l|}
\hline Ranks & N & Mean Rank & Sum of Ranks & Z & P \\
\hline Negative Ranks & 1 & 1.50 & 1.50 & \multirow{3}{*}{2.499} & \multirow{2}{*}{0.012} \\
\hline Positive Ranks & 8 & 5.44 & 43.50 & & \\
\cline { 1 - 3 } Ties & 1 & & & \\
\hline
\end{tabular}

Looking through the results in table (5), it is clear that the value of Zobs $=2.499$ is more than the critical value for a two-tailed test $\mathrm{Zcv}=1.96$ at significance level of $(0.05)$, which means that there is statistically significant difference between mean rank scores of the control group students in the pre and post applications of VAT. The total of the positive ranks $\sum \mathrm{R}+=43.50$ is more than the total of the negative ranks $\sum \mathrm{R}-=1.50$. This difference goes to the favor of the post application. In the light of this result, the null hypothesis (H0) is rejected and the alternative hypothesis (H1) is accepted.

The alternative directed hypothesis states that "There is a statistically significant difference at $(\alpha \leq 0.05)$ level between the mean rank scores obtained by the students of the control group in the pre and post applications of the vocabulary achievement test (VAT) to the favor of the post application".

\subsection{Testing the fourth hypothesis}

The fourth hypothesis states that "There is no statistically significant difference at level $(\alpha \leq 0.05)$ between the mean rank scores obtained by the students of the experimental group in the pre and post applications of the vocabulary achievement test (VAT)".

To test this hypothesis, Wilcoxon Signed Ranks Test, the non - parametric alternative of T test for two related samples, was used. $\mathrm{Z}$ value, the alternative normal distribution of Wilcoxon value, was also calculated as shown in the following table (6): 
Table (6): Wilcoxon Signed Ranks value for comparing mean ranks of the experimental group in the pre and post applications of VAT.

\begin{tabular}{|c|c|c|c|c|c|c|}
\hline Ranks & $\mathrm{N}$ & Mean Rank & Sum of Ranks & Z & $\mathrm{P}$ & $\begin{array}{l}\text { Effect Size } \\
\text { (ES) }\end{array}$ \\
\hline Negative Ranks & 0 & .00 & .00 & \multirow{3}{*}{3.061} & \multirow{3}{*}{0.01} & \multirow{3}{*}{0.88} \\
\hline Positive Ranks & 12 & 6.50 & 78.00 & & & \\
\hline Ties & 0 & & & & & \\
\hline
\end{tabular}

Looking through the results in table (6), it is clear that the value of Zobs $=3.061$ is more than the critical value of a two-tailed test $\mathrm{Zcv}=1.96$ at significance level of $(0.05)$, which means that there is statistically significant difference between the mean rank scores of students in the pre and post applications of VAT. The total of the positive ranks $\sum \mathrm{R}+=6.50$ is more than the total of the negative ranks $\sum \mathrm{R}-=0$. This difference goes to the favor of the post application. In the light of this result, the null hypothesis (H0) is rejected and the alternative hypothesis (H1) is accepted.

The alternative directed hypothesis states that " There is a statistically significant difference at $(\alpha \leq 0.05)$ level between the mean rank scores obtained by the students of the experimental group in the pre and post applications of the vocabulary achievement test (VAT) to the favor of the post application".

This result is in line with the results of Hettiarachchi \& Ranaweera (2013), Obaid (2013), Tolbert(2013) and Ashouri \& Moghadam (2015).They all agreed that the students who were taught via the multisensory method scored high results in the posttest which means that the multisensory method is effective in enhancing students achievement.

\subsection{Testing the fifth hypothesis}

The fifth hypothesis states that "There is no statistically significant difference at level $(\alpha \leq 0.05)$ between the mean rank scores obtained by the students of the control group in the post and delayed applications of the vocabulary achievement test (VAT)".

To test this hypothesis, Wilcoxon Signed Ranks Test, the non - parametric alternative of T test for two related samples, was used. $\mathrm{Z}$ value, the alternative normal distribution of Wilcoxon value, was also calculated as shown in the following table (6):

Table (7): Wilcoxon Signed Ranks value for comparing mean ranks of the control group in the post and delayed applications of VAT.

\begin{tabular}{|c|c|c|c|c|c|}
\hline Ranks & $\mathrm{N}$ & Mean Rank & Sum of Ranks & $\mathrm{Z}$ & $\mathrm{P}$ \\
\hline Negative Ranks & 6 & 5.83 & 35.00 & \multirow{3}{*}{0.767} & \multirow{3}{*}{0.443} \\
\hline Positive Ranks & 4 & 5.00 & 20.00 & & \\
\hline Ties & 0 & & & & \\
\hline
\end{tabular}

The results in table (7) show that, the value of Zobs $=0.767$ is less than the critical value for a two-tailed test $\mathrm{Zcv}=1.96$ at significance level of $(0.05)$, which means that there is no statistically significant difference between mean ranks of students' scores in the post and delayed applications of VAT. In the light of this result, the null hypothesis (H0) is accepted.

To understand this result, we should revise students mean scores in the post and delayed tests. The results in tables $(1,3)$ show that the mean scores obtained by the students of the control group is $(8.4000)$ in the posttest and (7.4000) in the delayed test. Comparing these results to the results of the experimental group that were (28.9167) and (23.5000) respectively shows that the number of vocabularies that were obtained by the control group, which were taught by the traditional method, was very little. This justifies the convergent results of the control group in the post and delayed tests.

\subsection{Testing the sixth hypothesis}

The sixth hypothesis states that "There is no statistically significant difference at level $(\alpha \leq 0.05)$ between the mean rank scores obtained by the students of the experimental group in the post and delayed applications of the vocabulary achievement test (VAT)".

To test this hypothesis, Wilcoxon Signed Ranks Test, the non - parametric alternative of T test for two related samples, was used. $Z$ value, the alternative normal distribution of Wilcoxon value, was also calculated as shown in the following table (8):

Table (8): Wilcoxon Signed Ranks value for comparing mean ranks of the experimental group in the post and delayed applications of VAT.

\begin{tabular}{|l|l|l|l|l|l|}
\hline Ranks & N & Mean Rank & Sum of Ranks & Z & P \\
\hline Negative Ranks & 10 & 6.40 & 64.00 & \multirow{3}{*}{0.006} \\
\hline Positive Ranks & 1 & 2.00 & 2.00 & & \multirow{2}{*}{0.763} \\
\hline Ties & 1 & & & & \\
\hline
\end{tabular}


The results in table (8) show that, the value of Zobs $=2.763$ is more than the critical value of a two-tailed test $\mathrm{Zcv}=1.96$ at significance level of $(0.05)$, which means that there is statistically significant difference between the students' mean rank scores in the post and delayed applications of VAT. The total of the positive ranks $\sum \mathrm{R}+=2.00$ is more than the total of the negative ranks $\sum \mathrm{R}-=46.00$. This difference goes to the favor of the post application. In the light of this result, the null hypothesis (H0) is rejected and the alternative hypothesis (H1) is accepted.

The alternative directed hypothesis states that "There is a statistically significant difference at $(\alpha \leq 0.05)$ level between the mean rank scores obtained by the students of the experimental group in the post and delayed applications of the vocabulary achievement test (VAT) to the favor of the post application".

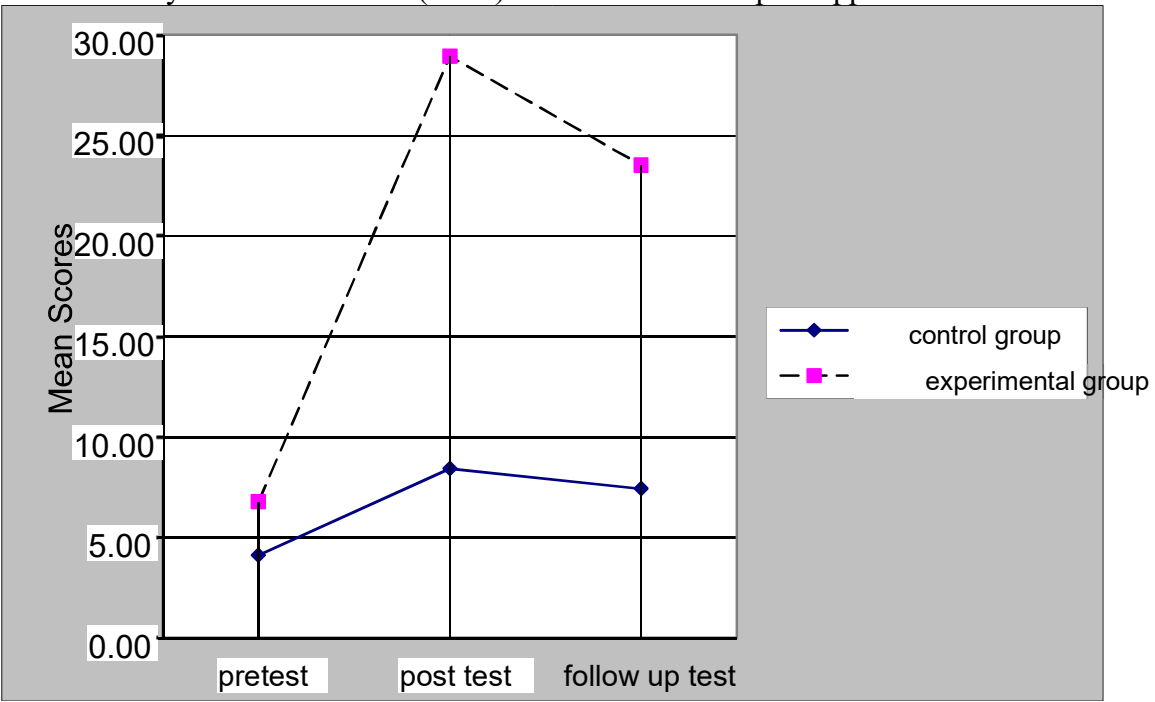

Figure 1: performance of the students enrolled in the experimental and control groups in the pre, post and delayed tests.

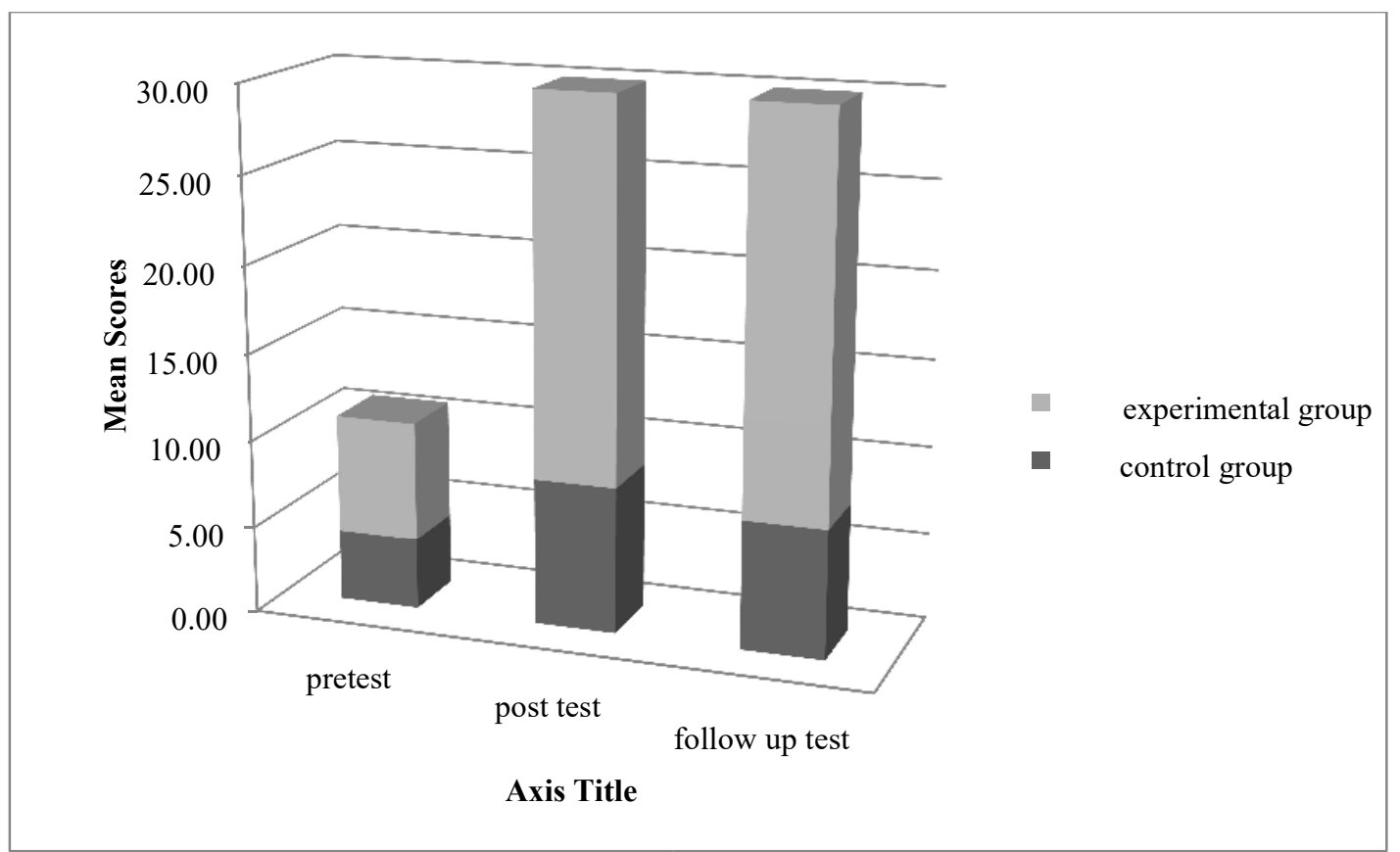

Figure 2: performance of the students enrolled in the experimental and control groups in the pre, post and delayed tests.

Figures $(1,2)$ show the performance of the students enrolled in the experimental and control groups in the pre, post and delayed applications of VAT. The figures clarify that students of the experimental group outperformed those of their counterpart enrolled in the control group in both the post and delayed applications of 
the VAT.

\section{Conclusion}

The current study provided evidence to the effectiveness of using multisensory approach in enhancing vocabulary achievement. Besides, it provided evidence to the effectiveness of using multisensory approach in enhancing vocabulary retention. The results showed that using all the senses in learning English vocabulary helped students with learning disabilities to overcome their learning disabilities. Furthermore, the proposed model was proved to be effective in enhancing English vocabulary achievement for students with learning disabilities. Finally, the teacher's guide of the present study was proved to facilitate teaching English vocabulary for second grade female students with learning disabilities.

\section{References}

Academy of Orton-Gillingham Practitioners and Educators. (2012). The Orton-Gillingham Approach. Retrieved on February 15,2014 from: http://www.ortonacademy.org/approach.php

Al-Zahrani, M. A. B. (2011). The Effectiveness of Keyword-Based Instruction in Enhancing English Vocabulary Achievement and Retention of Intermediate Stage Pupils with Different Working Memory Capacities. Online Submission.

Asghar, A., Sladeczek, I. E., Mercier, J., \& Beaudoin, E. (2017). Learning in science, technology, engineering, and mathematics: Supporting students with learning disabilities. Canadian Psychology/Psychologie canadienne, 58(3), 238.

Ashoori, P., \& Moghadam, M. (2015). The effect of instructing mnemonic devices on immediate versus delayed vocabulary retention. International Journal of Language Learning and Applied Linguistics World, 8(1), 87102.

Bromley, K. (2007). Nine things every teacher should know about words and vocabulary instruction. Journal of adolescent \& adult literacy, 50(7), 528-537.

Chau, M. (2011). Connecting learning styles and multiple intelligences theories through learning strategies: an online tutorial for library instruction.

Corbett, L. D. (2009). The Effect of Vocabulary Instruction on the Reading Achievement of at Risk Third-Grade Students. ProQuest LLC. 789 East Eisenhower Parkway, PO Box 1346, Ann Arbor, MI 48106.

D'Alesio, R., Scalia, M. T., \& Zabel, R. M. (2007). Improving Vocabulary Acquisition with Multisensory Instruction. Online Submission.

Dev, P. C., Doyle, B. A., \& Valente, B. (2002). Labels needn't stick:" At-risk" first graders rescued with appropriate intervention. Journal of Education for Students Placed at Risk, 7(3), 327-332.

Farlex, (2009). The Online Free Dictionary. Retrieved November 1,2014 from: http://www.thefreedictionary.com/multisensory

García, M., \& Dolores, M. (2010). Multisensory learning applied to TEFL in secondary education. Spain: Complutense University of Madrid.

García, M., \& Dolores, M. (2010). Multisensory learning applied to TEFL in secondary education. Spain: Complutense University of Madrid.

Hettiarachchi, S., \& Ranaweera, M. (2013). Story Boxes: using a multisensory story approach to develop vocabulary in children experiencing language-learning difficulties.

Jones ,S. (2005). Multisensory vocabulary instruction: Guidelines and activities. Retrieved from http://www.readingrockets.org/article/286

Joshi, R. M., Dahlgren, M., \& Boulware-Gooden, R. (2002). Teaching reading in an inner city school through a multisensory teaching approach. Annals of Dyslexia, 52(1), 229-242.

Joshi, R. M., Dahlgren, M., \& Boulware-Gooden, R. (2002). Teaching reading in an inner city school through a multisensory teaching approach. Annals of Dyslexia, 52(1), 229-242.

Jubran, S. (2012). USING MULTI SENSORY APPROACH FOR TEACHING ENGLISH SKILLS AND ITS EFFECT ON STUDENTS'ACHIEVEMENT AT JORDANIAN SCHOOLS. European Scientific Journal, 8(22).

Keshta, A. S., \& Al-Faleet, F. K. (2013). The effectiveness of using puzzles in developing Palestinian tenth graders' vocabulary achievement and retention. Humanities and Social Sciences, 1(1), 46-57.

Kirk, S. A., \& Chalfant, J. C. (1984). Academic and developmental learning disabilities. Love Pub Co.

Komachali, M. E., \& Khodareza, M. (2012). The Effect of Using Vocabulary Flash Card on Iranian Pre-University Students' Vocabulary Knowledge. International Education Studies, 5(3), 134-147.

Komachali, M. E., \& Khodareza, M. (2012). The Effect of Using Vocabulary Flash Card on Iranian Pre-University Students' Vocabulary Knowledge. International Education Studies, 5(3), 134-147.

Learning Disability Association of America. (2015). Types of Learning Disabilities. Retrieved on February 13, 2015 from: http://ldaamerica.org/types-of-learning-disabilities/ 
Lin, S. F. (2003). Modeling a supplemental course web site for EFL vocabulary acquisition (pp. 1-198). University of Delaware.

Luke, S. D. (2011). National Dissemination Center for Children with Disabilities. Encyclopedia of Clinical Neuropsychology, 1707-1707.

Moustafa, B. M. (1999). Multisensory Approaches and Learning Styles Theory in the Elementary School: Summary of Reference Papers.

Murphy, N. (1997). A Multisensory vs. Conventional Approach to Teaching Spelling.

National Council for Special Education (NCSE). (2014). Children with Special Educational Needs: information booklet for parents.

National Joint Committee on Learning Disabilities. (1998). Operationalizing the NJCLD definition of learning disabilities for ongoing assessment in schools. Learning Disability Quarterly, 186-193.

National Reading Panel (US), National Institute of Child Health, \& Human Development (US). (2000). Teaching children to read: An evidence-based assessment of the scientific research literature on reading and its implications for reading instruction. National Institute of Child Health and Human Development, National Institutes of Health.

Nemati, A. (2009). Memory vocabulary learning strategies and long-term retention. International Journal of Vocational and Technical Education, 1(2), 014-024.

Phillips, W. E., \& Feng, J. (2012). Methods for Sight Word Recognition in Kindergarten: Traditional Flashcard Method vs. Multisensory Approach. Online Submission.

Pickering, J. S. (2004). The At Risk child: How the Montessori classroom enhances learning: Part 1. Montessori life, 16(1), 8 .

The International Dyslexia Association. (2000). Orton-Gillingham-Based and /or Multisensory Structured language Approaches. Retrieved on October 2014 from: http://www.dysadd.com/resources/Myths/IDA.OG.Fact.Sheet.pdf

Tolbert, J. (2013). The effects of guided visual vocabulary practice for students with learning disabilities on learning concrete nouns in Spanish.

Turnbull III, H. R. (2005). Individuals with disabilities education act reauthorization: Accountability and personal responsibility. Remedial and Special Education, 26(6), 320-326.

Viskari, K. (2005). Foreign language learning disabilities: Theoretical and practical tools for English teachers in Finnish upper secondary schools.

Voltz, D. L., Sims, M. J., \& Nelson, B. (2010). Connecting Teachers, Students, and Standards: Strategies for Success in Diverse and Inclusive Classrooms: Strategies for Success in Diverse and Inclusive Classrooms. ASCD. 